\title{
Methods of Reflection about Service Learning: Guided vs. Free, Dialogic vs. Expressive, and Public vs. Private
}

\section{ABSTRACT}

Reflection is a key component of service learning, but research shows that in order to maximize learning, the reflection must be of high quality. This paper compares the affordances of three different models of written reflection in engendering students' higher-order thought processes. Student reflections were compared across axes of guided versus free response, dialogic versus expressive reflection, and public versus private reflection. Results indicate that guided reflection yields more response than free reflection does. Dialogic and guided reflections both yield more integration of knowledge from service learning activities within a larger context. Results for public reflection versus private were mixed. Ethical considerations for public reflection are also discussed.

\section{KEYWORDS}

reflection, applied learning, experiential learning, service learning, blogs

As instructors work with students to meet course objectives through service learning, intentional reflection about the process is an important way for students to integrate knowledge of theory with experience in practice. In fields where direct service is not a goal of the discipline-for example, in business or communications - engaging students in effective reflection can be a challenge, as it may be more difficult to convince students of the need for it. This is unfortunate because reflection will be an essential part of successfully integrating their knowledge into a professional context.

Reflection has been well studied and is key to distinguishing service learning from volunteering. There are many types of reflection, including group discussion, partner interactions, and other face-to-face opportunities. This paper investigates the affordances of different types of written reflection along three dimensions. We examine the reflections of students enrolled in multiple sections of an international service learning class. Cases are drawn from the same cohort of students, who are doing similar projects, but engaging in different methods of reflection. Their level of critical thinking about the service experience is coded and compared. 


\section{RELATED LITERATURE}

\section{Service learning}

Academic service learning is usually characterized as one of several forms of experiential learning. It is a pedagogy that allows students to connect theories learned in class with hands-on practice (Applegate \& Morreale, 2006; Perkins, Kidd, \& Smith, 2006; Soukup, 2006; Whitney \& Clayton, 2011). Saltmarsh (1997) describes the linked understandings that service learning allows students to form between their academic learning and their community partners - including the contexts in which these partners live and work-as "connected knowing" (p. 81). Service learning encourages students to take responsibility for their own learning by involving them in real-world problems that are set in authentic communities (Brown, 2011; Perkins et al., 2006).

Service learning also permits students to learn in situations in which they aren't the only beneficiaries of the learning process; community partners also receive value (Applegate \& Morreale, 2006). Service learning can help students better understand issues related to community engagement, including intercultural awareness (Deardorff \& Edwards, 2013) and diversity (Zlotowski, 2007). Furthermore, it can allow students to better understand themselves as learners and as future practitioners in their field of study (Carrington \& Selva, 2010), while also increasing their sense of civic responsibility (Urraca, Ledoux, \& Harris, 2009).

\section{Reflection}

Dewey (1933) is generally credited as being the first scholar to posit that reflection is an important aspect of the learning process, especially when students need to integrate their active experiences into the context of what they are learning. Schön (1983) advances Dewey's thinking by distinguishing between reflection that helps students process what happens during an activity (reflection-in-action) and reflection that helps students process what they have learned after an activity (reflection-on-action), both of which can be valuable components of experiential learning activities like service learning. Reflection is also an important aspect of the educational philosophy of constructivism, which says that people learn by reflecting on what they already know and then integrating that knowledge with new concepts (Russo \& Ford, 2006). Dyment and O'Connell (2011) believe that regardless of format or specific purpose, written reflections can help students develop both personally and professionally. Herington and Weaven (2008) suggest that surface learning approaches direct students toward rehearsal behavior, while reflection is an important aspect of deeper approaches to student learning. Russo and Ford (2006) describe reflection as one of the fundamental components of the Scholarship of Teaching and Learning (SoTL).

Reflection has been called "a core component of service learning” (Boyle-Baise et al., 2006; Connors \& Siefer, 2005). It is, according to Eyler (2001), "the hyphen in service learning" as it helps students connect what they observe and experience in the community with the material they learn in the classroom. Benefits include the abilities to integrate theory and practice (Soukup, 2006), construct meanings for present and future actions (Moon, 1999), develop deeper understandings of subject matter (Eyler, 2001), and examine one's assumptions about an experience (Eyler, 2002). Reflection can also 
help students engage with the communities in which they work (Maher, 2003), enhancing relationships with community partners, as students can use their thinking to assess the success of the partnership even during the process of the collaboration, modifying their actions as needed. Reflection is not always used in service learning classes, although research shows it to be beneficial (Ash \& Clayton, 2009): it can separate service learning from simple volunteering (Dunlap, 1998) and help students synthesize the service they perform with academic content (Boyle-Baise et al., 2006). As Turnley notes (2007), students can use reflection to place the practice of their respective disciplines in a larger context of the field.

Reflection is not automatic for students, especially effective reflection. The costs of ineffective reflection can be high: poor reflection can lead to inadequate or flawed connections between the actions of service and the concepts of learning. Poor reflection can even reinforce flawed thinking, if inaccurate assumptions remain unchallenged (Ash \& Clayton, 2004). The quality of the reflection can also affect the quality of the service. For example, Turnley (2007) suggests that reflection in action can lead to superior development of products for community partners. Quinton and Smallbone (2010) advance this thinking by suggesting that reflection becomes a more valuable tool when faculty provide formative feedback that students subsequently engage with to promote higher-order critical thinking.

Folkestad, Senior, and DeMiranda (2002) posit that reflection is one of the most neglected parts of service learning. In applied fields, such as business, health professions, or communications where experiential learning helps students practice skills in a more authentic environment (Motley \& Sturgill, 2013), the goals of reflection may be less obvious. For example, in fields where direct human service is not an element of professional practice, instructors may struggle to develop meaningful reflection opportunities for students because the link between service and professional practice is not as clear (Folkestad et al., 2002). Business students, for instance, may engage in service learning activities in order to practice business skills, such as marketing or entrepreneurship. Since maximizing utility for shareholders is a key goal of business (Yunus, 2009), the service may be a means to an end rather than an end unto itself.

Oster-Aaland, Sellnow, Nelson, and Person (2004) note that the number of communications departments that offer at least some service learning opportunities for students is increasing, but the number that require a structured reflection component is decreasing. How important is structure to successful reflection? What elements are significant in enhancing the quality of student thinking in a reflection process? Finally, although types of reflection have been evaluated, the incorporation of new media applications as a reflection technique has not been well studied in comparison with other, more traditional methods of reflection. What is the effect of modes of new media on such reflection? This paper reflects an attempt to study these questions empirically.

\section{Models for the relation between reflection and cognition}

Eyler (2002) believes that maximum value to the student occurs when reflection is incorporated into academic service learning before, during, and after students' experiences in a community. Terry and Bohnenberger (2004) suggest that reflection has multiple levels, including observation, analysis, and synthesis. In their model, higher levels of reflection are equivalent to higher-order learning. Marchel (2004) suggests a similar 
typology, in which student reflections can be considered descriptive (what happens), analytic (why things happen), and integrated (how the student's actions affect others). Again, integrated reflection indicates higher-order thought processes.

There are many different models for reflection, among them reflection with and without guiding feedback (Quinton \& Smallbone, 2010), verbal and written reflection (Maher, 2003), reflection with or without community partners, and reflection with and without guiding feedback. This paper considers some of the effects of the mode of reflection on student learning. In particular, we were interested in three dimensions of variation in written reflection assignments.

\section{Guided vs. free}

First is guided versus free reflection. In a guided reflection, the instructor provides prompts or other expert indicators of the appropriate structure and content of student reflections. In a free reflection, students are asked to write their reflections (in, say, a journal or on a blog), but as they are not given specific prompts, they construct their own knowledge about meaningful topics.

Guided reflection helps students reflect on matters relevant to course goals. For the instructor, a known set of reflections can be useful in monitoring or, if necessary, modifying the project as it proceeds. To facilitate assessment, guided reflection can be useful in generating a common set of artifacts related to course objectives, enabling instructors to make comparisons across students. Finally, if written reflection is complemented by other forms, such as classroom or small-group discussion, guided reflection can offer a common base of thought to draw from as students begin these conversations.

Free reflection has affordances as well. Students may come up with unanticipated domains for reflection that can prove valuable in processing their service experience. Having a variety of thoughts and experiences to share in class can be enriching for the students. For the instructor, having a varied set of written reflections to read is less tedious. It's possible, however, that students could use free reflection as an excuse to put less work into their responses, since their entries aren't required to meet a set standard of length or quality.

To compare these types of reflections, we asked two research questions (RQs). First, does guided reflection lead to more examples of higher-order thinking (RQ1)? Second, does guided reflection lead to longer reflections, which would suggest at minimum that students spent more time in preparing the longer reflections and potentially that students engaged in more thinking in order to create more text (RQ2)?

\section{Dialogic vs. expressive}

Next, we considered dialogic and expressive models. In a dialogic model, student reflections are shared with and commented on by others - the instructor and perhaps other students or community partners - throughout the service learning experience. In an expressive model, students are required to complete reflections, but their writing does not receive feedback until the end of the semester.

Again, there are affordances for each model. In a dialogic model, the guidance and shaping of thought processes can focus the reflections and reinforce key concepts. The instructor can also use interim commenting to generate goals for the students, which later can become gradable elements. If the students engage in the dialog, this creates 
another learning opportunity for them as they comment on the reflections of others. In an expressive model, students may feel less need to filter their reflections, which could result in more authentic, varied responses that address areas of student concern outside of the ones pre-determined by the instructor. In such reflection without intervention or interaction, a student may engage in a lower level of critical thinking throughout the experience, which could represent a lost opportunity in terms of the value of the reflection. We wondered if dialogic reflection leads to more high-order thinking (RQ3).

\section{Public vs. private}

The final dimension is public versus private. A private reflection is one that is only accessible to persons involved with the service learning project. Although reflections are often kept as written journals, asking students to reflect on a blog or discussion board makes them accessible as public reflections. The public element introduces a wider audience, which might affect the value of the reflection. In a public reflection, students may be motivated to think about the needs and attitudes of prospective readers. This could cause students to make more careful analysis, or it could cause them to be more reserved for fear of attracting criticism.

Private reflections have the important advantage of protecting the confidentiality of the service site and its clients, as well as that of students, who might make comments out of inexperience that they will later regret. Private reflections could improve aspects of the reflection, as students would not self-censor for the benefit of the audience, but may consider issues more frankly. In particular, when service learning is done in a group, students who know that their reflections are private may consider group process more explicitly in their reflections without fear of insulting colleagues.

There are some benefits to public reflection. The content of the students' reflections would be accessible to other students and to scholars interested in analyzing the reflection process. A public reflection can also extend the dialog outside of the class, bringing into the conversation students from other majors, citizen groups, parents, and other interested parties who may become involved in a discussion of the issues brought about by the service. Public reflection can also be a convenient way to facilitate conversation between the community partners and students about issues the students see and how they interpret them. This could encourage students to consider more sides of an issue. We thus wondered if public reflection encourages more high-order thinking (RQ4).

\section{METHODOLOGY}

Four sections of a one-month, graduate, international service learning course in interactive media were studied. Students in one of four groups of seven to nine students worked with a community partner to produce an interactive project for that partner's chosen audience, to the partner's specifications. The students were enrolled in a professional master's degree program in communications at a medium-sized liberal arts university in the southern United States in a cohort of 34. All students were required to complete the international experience. Instructors chose the community partners in advance of the trip; however, students were expected to negotiate the content and structure of the interactive project with the community partner. In all cases, visibility in the larger community was the primary need of the partners, so the students collected multimedia content as well as independent research, and then built an artifact (a CD-Rom or website) to help with 
this need. All four sections went to a Latin American country. Each team had a different university instructor and an assistant (and, in three cases, a translator). The authors were instructors for two of the sections. This research was vetted by the institution's internal review board, and students gave informed consent to have blinded comments used in this study.

\section{Data collection}

The type of reflection required of the students varied by instructor. In the first group (Alpha), students individually contributed to a group, public blog. Almost all of the students participated, but the number of posts per student varied. Alpha students engaged in public, expressive, free reflection. Although a blog could be dialogic, in this case no one commented on the posts. The three other groups were required to keep paper journals. In the first of these (Beta), the instructor assigned a regular set of daily prompts along with a question related to that day's issues. Journals were collected twice, and the instructor read the entries and gave written commentary. Journal entries were discussed, but this didn't happen in every meeting. Beta students engaged in private, dialogic, guided reflection. In the next group (Gamma), journal-keepers responded to daily prompts as well as a daily instructor-choice question. The instructor did not read journals until the end of the course. Gamma students engaged in private, expressive, guided reflection. In the final group (Delta), students kept a journal, but had no stipulations as to content. Journals were not read until the end of the course. Delta students engaged in private, expressive, free reflection.

\section{Analysis}

All journal and blog entries were analyzed for this paper. Two coders working in tandem analyzed each paragraph, and discussion was used until consensus through a threelevel coding system. The system was modeled on a rubric developed by Bradley (1995) to assess the development of "the thought characteristic of highly skilled professionals who work in complex situations" (p. 19). Levels of reflection were operationalized as descriptive, analytical, and integrative. In the descriptive level, the writing delineated a student's activities, such as "Today was by far my most favorite day. I love the beautiful nature and the tours. Getting to see where people live felt really sincere and I felt as if I had the opportunity to see how real (redacted to protect confidentiality) live from day to day. The food was really good also." In analytical paragraphs, the student assessed the effects of activities on the project itself, which could produce benefits for the community partner or the student-created artifact—for example, "One thing I noticed, though, is everyone has different things and styles they like to shoot from regardless of what camera they are using, which will add some diversity to our content." Finally, in integrative paragraphs, the student assessed the impact of project activities on issues larger than the individual project, such as the student's education or future career, or even global issues. An example is "As exciting as it was, we still had to keep our guard up. There were some locals who did not appreciate their pictures being taken, but others begged us out on the streets as we drove by to take their picture. Some loved us; some were annoyed by us. Apparently that is the overall feeling about Americans. There are some with grievances against us, while some welcome the attention. It's interesting considering that most of their economy depends upon tourism and our money." We assumed that the relationship of descriptive, analytic, 
and integrative was in some sense ordinal: descriptive writing demonstrated less critical thinking than did analytic, which demonstrated less than did integrative.

Finally, there were elements in some of the journals that did not relate to the class or project at all. These were coded as "other," such as "Looking at the world from a window seat of a plane somehow forces you to think and be real with yourself. What is it about this world that allows us to pump our heads up so freely? What is it that governs our minds so strictly and ignorantly that we constantly think inside the box and not outside of it?"

A total of 1,404 paragraphs were read and discussed individually until coders agreed on a category for each. Each paragraph was assessed for the idea within that showed the highest level of thinking, which was then the coding of the paragraph. For example, if a paragraph began with description of a project activity and then went on to evaluate the effect of the activity on the project as a whole, that paragraph was coded as analytic.

During the project, member checks were used by asking the faculty members and students their opinions on what was happening and after the fact on the accuracy of the coding. Also, as a validity check, a faculty member who taught a section of the course, but was not involved in the coding, evaluated all of the thematic groupings and their contents for consonance with his experiences. At the completion of the analysis, one of the accompanying interpreters who worked closely with the students also commented on the data and its analysis as a reflexivity check. Codes were recorded in a spreadsheet and crosstabulated, then converted to percentages to enable comparisons.

\section{RESULTS}

\section{Guided vs. free}

As Table 1 indicates, guided reflection generated more analytic and integrative paragraphs than free reflection did. More than half of the free reflections were descriptive only, and more than 10 percent were off-topic. This suggests that the answer to Research Question 1-Does using guided reflection lead to more higher-order thinking? - is yes.

Table 1. Comparison of types of reflection by guided or free mode of work

\begin{tabular}{lccccc} 
& DESCRIPTIVE & ANALYTICAL & INTEGRATIVE & OFF-TOPIC & TOTAL \\
\hline Guided & $230(25 \%)$ & $431(47 \%)$ & $251(27 \%)$ & $14(2 \%)$ & 926 \\
\hline Free & $269(56 \%)$ & $51(11 \%)$ & $105(22 \%)$ & $53(11 \%)$ & 478 \\
\hline Total & 499 & 482 & 356 & 67 & 1,404 \\
\hline
\end{tabular}

For Research Question 2, we compared the journals based on the number of paragraphs coded. There were two sections each given guided and free journal assignments. The guided journals yielded 926 paragraphs; the free journals, 478 . This suggests that the answer to Research Question 2-Does using guided reflection lead to longer reflections? is yes.

\section{Dialogic vs. expressive}

Results were mixed for Research Question 3. Table 2 compares the levels of thinking in dialogic journals with instructor feedback during the course with those that were expressive, having feedback only at the end of the course or not at all. Overall, the dialogic model seemed to produce higher-level thought, with 74 percent of paragraphs falling in 
the analytic or integrative level. However, the expressive journals were somewhat higher in integrative content-nearly 30 percent, compared with 22 percent of dialogic journal paragraphs reaching that level.

Table 2. Comparison of types of reflection by dialogic or expressive mode of work

\begin{tabular}{lccccc} 
& DESCRIPTIVE & ANALYTICAL & INTEGRATIVE & OFF-TOPIC & TOTAL \\
\hline Dialogic & $93(24 \%)$ & $202(52 \%)$ & $86(22 \%)$ & $5(1 \%)$ & 386 \\
\hline Expressive & $406(40 \%)$ & $280(28 \%)$ & $270(27 \%)$ & $62(6 \%)$ & 1,018 \\
\hline Total & 499 & 482 & 356 & 67 & 1,404 \\
\hline
\end{tabular}

\section{Public vs. private}

The finding for Research Question 4 is more difficult to interpret. As Table 3 indicates, private journal paragraphs were more likely to be analytic or integrative-64 percent, compared with 41 percent of the public journals. However, nearly one-third of the public reflections were integrative, suggesting that a public mode of reflection encourages students to think about big-picture issues. Thus results for Research Question 4-Did public reflection encourage more high-order thinking? — are mixed.

Table 3. Comparison of types of reflection by public or private status

\begin{tabular}{lccccc} 
& DESCRIPTIVE & ANALYTICAL & INTEGRATIVE & OFF-TOPIC & TOTAL \\
\hline Public & $140(51 \%)$ & $26(9 \%)$ & $85(31 \%)$ & $25(9 \%)$ & 276 \\
\hline Private & $359(32 \%)$ & $456(40 \%)$ & $271(24 \%)$ & $42(4 \%)$ & 1,128 \\
\hline Total & 499 & 482 & 356 & 67 & 1,404 \\
\hline
\end{tabular}

Finally, although off-topic paragraphs were not extremely common, they occurred more frequently in public, expressive, and free reflections.

\section{DISCUSSION}

Different methods of written reflection have different affordances for students and instructors in service learning projects.

\section{Guided vs. free}

Guided reflections were more thoughtful. Students in the guided group were required to answer the following questions each day:

1. What did you do today?

2. What did this mean for the client?

3. What did this mean for the project?

4. A question of the instructor's choosing.

Although the first question tended to draw descriptive responses, the others encouraged at least analytic and, for some students, integrative reflection. A typical response to the first question was "Today we met with (redacted) to discuss what we will be doing and what they would like to see out of the site. After, (redacted) and I met to get some basic ideas together for design." When the same student answered question 2 , the stu- 
dent wrote, "Prior to the meeting, I was expecting some degree of freedom in our direction, design, etc. Now, we understand that they already have a clear idea of what they want. The meeting today was a sort of establishing boundaries. While I'm not excited that the design group will be more constrained than I expected, I am thankful to know now. And also, this is the nature of the business." In general, asking meaningful questions led to meaningful reflections. Guided reflection also produced nearly twice as many paragraphs.

\section{Dialogic vs. expressive}

When giving interim feedback to students, a dialogic model has the advantage of allowing faculty to discern student thinking and provide feedback that can direct that thinking into instructive areas. One drawback, however, is that grade-conscious students might feel the need to align their thoughts with the "correct" answer, creating a sort of a Hawthorne Effect as the students try to please the professor. Dialog with the students came in two forms. First, the instructor who used it offered written responses to student journal entries, which were collected during the course of the project. Second, the instructor was able to add additional reflection questions during the process (several days had "instructor's choice" questions reserved for these opportunities). The additional questions were based on observations of student work and of their conversations.

Our work found that reflections completed in a dialogic mode had a higher percentage of analytic and integrative responses than those completed in an expressive mode. A good example of a dialogic interaction occurred when an instructor read the following in a student's reflections: "It is tempting for us to try and re-orient the focus (redacted) to a more materialistic, scientific approach. Americans tend to look at numerical outcomes and statistics to measure success. (redacted) simply creates a space for (redacted) to hold onto their human dignity and contribute to society like everyone else. I can respect that philosophy, even if it means it does not produce the results my American mind might not think are 'right."' The instructor shared this at a group meeting and asked students to reflect on this issue in their own journals.

In this case, an integrative reflection from one student led to integrative reflections from other students, such as "Every place has a different culture, religion, society that is to be respected. Americans make the mistake that everyone wants to speak English or do things the way we do. That attitude is what makes all kinds of nations resent us."

\section{Public vs. private}

Public reflection has advantages, including greater participation and the heightened focus that writing for an audience can bring. For these students, public reflection led to a higher level of integrative reflection. One example of integrative reflection from this group is as follows: "We were told that we might not be able to go into the jungles and see these people because it would be too dangerous for us. This caused me to wonder: what about the people who live there? What about their elderly and their young children? How do these people deal with all this flooding?" However, public reflection also led to a lot of description, such as the following:

Fun Moments of the Day:

1. Bought my sun hat ${ }^{*}$ finally*

2. Took a picture of willing, army men in the back of a military vehicle 
3. Shook the hand of a local selling merchandise on the street amidst heavy traffic

4. Drove down a one way street and almost got hit by two large trucks

5. Got lost ...... twice

6. Haggled with a merchant

7. Blown kisses at from the streets

Public reflection has one serious drawback: the difficulty of maintaining confidentiality for the community partner and for students. It's unlikely that a student writing publicly would have written the following private reflection: "Americans are really naïve. On this trip alone, I've seen how hurt they can be when Americans mock or disrespect their culture.... We trusted (redacted) to show us her culture, and we embraced it." Students might be less inclined to critically examine their own cultures or identify specific people or issues if they know their thoughts will be accessible to the world. Also, it is vital that if public reflection is used, parties are very clear on what information can and cannot be shared in the public forum to preserve needed confidentiality.

Private reflection lets students take more risks in their responses. For example, when a student was guided to think about the central narrative developed in her project, she wrote, "It is tempting for us to drift away from our empowerment narrative and do one of education and prevention. I also think it would be interesting to ask (redacted) if they could, they would go back and seek better medical care. I wonder if they would want (redacted) back. It seems like a silly and insensitive question, but without their (redacted), they wouldn't have each other." Students writing for public consumption might not risk such a "silly and insensitive" question in their reflections.

\section{LIMITATIONS AND FUTURE RESEARCH}

Although this study offers several areas for consideration in assigning reflection experiences, it suffers from a lack of experimental control, which was sacrificed in favor of analyzing real-world experiences. A more rigorous assignment scheme would have allowed consideration of interaction effects as well. For example, does a guided, public journal encourage more, higher-order thinking than a guided, private one? As it stands now, because there were only four assignments that worked on multiple dimensions at once, it is impossible to determine what the effects of the individual characteristics of reflection are. Additional research that controls the assigned tasks more tightly would be useful. Also, the study did not address all potential uses of reflection. Instead, we chose to emphasize cognitive outcome of reflection as related to student learning. There was also evidence of processing of emotion and consideration of ethical issues, like being an outsider in a community, that were not coded and considered in this work, instead fitting into the "other" category. We thought the varying nature of the four projects would make it difficult to tell if any effects were due to the type of reflection or the nature of the experience itself. Finally, this research used an interpretivist model, which means the results may not be generalizable to other classes, students, or contexts. However, the results do suggest that some explicit faculty involvement before and during the reflection process is useful in encouraging students to engage in more integrative thinking in the context of writing and possibly to consider the more global ramifications of their service on those they serve. 
Amanda Sturgill is associate professor in Elon University's School of Communications, and teaches media writing, multimedia storytelling, social media and analytics, and global studies.

Phillip Motley is assistant professor of visual communication at Elon University, and teaches in the interactive media graduate program and undergraduate classes in web publishing and digital media convergence.

\section{REFERENCES}

Applegate, J., \& Morreale, S. (2006). Preface. In D. Droge \& B. Murphy (Eds.), Voices of strong democracy: Concepts and models for service learning in communication studies (pp. ix-xiv). Sterling, VA: Stylus.

Ash, S. L., \& Clayton, P. H. (2004). The articulated learning: An approach to guided reflection and assessment. Innovative Higher Education, 29(2), 137-154.

Ash, S. L., \& Clayton, P. H. (2009) Generating, deepening and documenting learning: The power of critical reflection in applied learning. Journal of Applied Learning in Higher Education, 1(1): 25-48.

Boyle-Baise, M., Brown, R., Hsu, M. C., Jones, D., Prakash, A., Rausch, M., ... \& Wahlquist, Z. (2006). Learning service or service learning: Enabling the civic. International Journal of Teaching and Learning in Higher Education, 18(1), 17-26.

Bradley, J. (1995). A model for evaluating student learning in academically based service. In M. Troppe (Ed.), Connecting cognition and action: Evaluation of student performance in service learning courses (pp. 13-26). Denver, CO: Education Commission of the States, Campus Compact.

Brown, N. (2011). A 360-degree view of international service learning. In R. Bringle, J. Hatcher, \& S. Jones (Eds.), International service learning: Conceptual frameworks and research (pp. 57-68). Sterling, VA: Stylus.

Carrington, S., \& Selva, G. (2010). Critical social theory and transformative learning: Evidence in pre-service teachers' service learning reflection logs. Higher Education Research \& Development, 29(1), 45-57.

Connors, K., \& Seifer, S.D. (2005, September). Reflection in higher education service learning. Community-Campus Partnerships for Health.

Deardorff, D., \& Edwards, K. (2013). Framing and assessing students' intercultural competence in service learning. In P. Clayton et al. (Eds.), Research on service learning: Conceptual frameworks and assessment, Volume 2A: Students and Faculty (pp. 157-186). Sterling, VA: Stylus.

Dewey, J. (1933). How we think. Boston, MA: D.C. Heath and Company.

Dunlap, M. R. (1998). Methods of supporting students' critical reflection in courses: Incorporating service learning. Teaching of Psychology, 25(3), 208-10.

Dyment, J. E., \& O'Connell, T. S. (2011). Assessing the quality of reflection in student journals: A review of the research. Teaching in Higher Education, 16(1), 81-97.

Eyler, J. (2001). Creating your reflection map. New directions for higher education, 2001(114), 35-43.

Eyler, J. (2002). Reflection: Linking service and learning — Linking students and communities. Journal of Social Issues, 58(3), 517-534. 
Folkestad, J. E., Senior, B. A., \& DeMirana, M. A. (2002). The implications of service- learning for technology studies. Journal of Technology Studies, 28(1), 52-58.

Herington, C., \& Weaven, S. (2008). Action research and reflection on student approaches to learning in large first year university classes. The Australian Educational Researcher, 35(3), 111-134.

Maher, M. J. (2003), Individual beliefs and cultural immersion in service learning: Examination of a reflection process. Journal of Experiential Education, 26(2) 88-96.

Marchel, C. (2004) Evaluating reflection and sociocultural awareness in service learning classes. Teaching of Psychology, 31(2), 120-123.

Moon, J. A. (1999). Reflection in learning and professional development: Theory and practice. New York, NY: Routledge Falmer.

Motley, P., and Sturgill, A. (2013) Assessing the merits of international service learning in developing professionalism in mass communication. Communication Teacher, 27(3), 172-189.

Oster-Aaland, L., Sellnow, T., Nelson, P., \& Pearson, J. (2004). The status of service learning in departments of communication: A follow-up study. Brief reports. Communication Education, 53(4), 348-356.

Perkins, S., Kidd, V., \& Smith, G. (2006). Service learning at the graduate level. In D. Droge \& B. Murphy (Eds.), Voices of strong democracy: Concepts and models for service learning in communication studies (pp. 35-46). Sterling, VA: Stylus.

Quinton, S., \& Smallbone, T. (2010). Feeding forward: Using feedback to promote student reflection and learning-a teaching model. Innovations in Education and Teaching International, 47(1), 125-135.

Russo, T. C., \& Ford, D. J. (2006). Teachers' reflection on reflection Practice. Journal of Cognitive Affective Learning, 2(2), 1-12.

Saltmarsh, J. (1997). Ethics, reflection, purpose, and compassion: Community service learning. New Directions for Student Services, 1997(77), 81-93.

Schön, D. A. (1983). The reflective practitioner: How professionals think in action. New York: Basic Books.

Soukup, P. (2006). Service learning in communication: Why? In D. Droge \& B. Murphy (Eds.), Voices of strong democracy: concepts and models for service learning in communication studies (pp. 7-12). Sterling, VA: Stylus Publishing.

Terry, A. W., \& Bohnenberger, J. E. (2004). Blueprint for incorporating service learning: A basic, developmental, K-12 service learning typology. Journal of Experiential Education, 27(1), 15-31.

Turnley, M. (2007). Integrating critical approaches to technology and service learning projects. Technical Communication Quarterly, 16(1), 103-123.

Urraca, B., Ledoux, M., \& Harris, J.T. (2009). Beyond the comfort zone: Lessons of intercultural service. The Clearing House: A Journal of Educational Strategies, Issues, and Ideas, 82(6), 281-289.

Whitney, B., \& Clayton, P. (2011). Research on and through reflection in international service learning. In R. Bringle, J. Hatcher, \& S. Jones (Eds.), International service learning: Conceptual frameworks and research (pp. 145-187). Sterling, VA: Stylus. 
Yunus, M. (2009). Creating a world without poverty: Social business and the future of capitalism. Philadelphia, PA: Public Affairs Books.

Zlotkowski, E. (2007). The case for service learning. In Macllrath, L., \& I. Mac Labhrainn (Eds.), Higher education and civic engagement: International perspectives (pp. 37-52). Burlington, VT: Ashgate Publishing. 